\title{
Comparison of Pre-Treatment with OndansetronVersus Tramadol For Reduction of Pain on Injection of Propofol-A Prospective, Randomised Study
}

\author{
Dr. Manali Nadkarni ${ }^{1}$, Dr.Jitendra Mahajan ${ }^{2}$ \\ I'Additional Professor, Department Of Anaesthesiology, Seth G. S. Medical College \&K.E.M.Hospital / India) \\ ${ }_{2}^{2}$ (Postgraduate Student, Department Of Anaesthesiology, Seth G.S.Medical College\&K.E.M.Hospital / India)
}

\begin{abstract}
:
Background and aims:Propofol is a commonly used intravenous induction agent. But a significant side effect of propofol is pain on injection. In this study our aim was to compare the effectiveness of ondansetron pretreatment versus tramadol pre-treatment in alleviating propofol injection pain. Method: 300 patients were randomly assigned to one of the following three groups. Group I received $2 \mathrm{ml}$ pre-treatment with $4 \mathrm{mg}$ ondansetronin normalsaline, group II received $2 \mathrm{ml}$ pre-treatment with $50 \mathrm{mg}$ tramadol in normal saline, and group III received pre-treatment with $2 \mathrm{ml}$ normal saline. A 20 gauge cannula was placed into the largest vein on the dorsum of the hand. Venous drainage was occluded by holding proximally by hand, and then the drug was injected. After 60 seconds, the occlusion was released and propofol $2 \mathrm{ml}$ was injected intravenously over 5 seconds and pain assessment was made. Results: Ondansetron and tramadolsignificantly reduced the incidence and severity of propofol injection pain more than placebo $(P=0.001)$. The efficacy of ondansetron in alleviating the pain on injection of propofol was no different from tramadol $(P=0.330)$. Ondansetron pre-treatment may be used to reduce the incidence of pain on injection of propofol, an advantage added to its action of prevention of postoperative nausea and vomiting.
\end{abstract}

Keywords: Ondansetron, pain on injection,pre-treatment, propofol, tramadol.

\section{Introduction}

Propofol is an intravenously administered induction agent causing hypnosis. It is mainly used for induction and maintenance of general anaesthesia, sedation in critical care units in adults, mechanically ventilated patients and procedural sedation, total intravenous anaesthesia, anticonvulsant and as an antiemetic ${ }^{1}$.Propofol is the drug of choice for induction of anaesthesia in millions of patients every year because of its rapid onset and short duration of action, easy titration and favourable profile for side effects ${ }^{1}$. Although it decreases the incidences of nausea and vomiting ${ }^{1}$,one of the disadvantages of propofol use for induction is the pain caused during injection ${ }^{1,2}$.The pain occurs in $28 \%-90 \%$ of patients ${ }^{3}$.Some patients recall the induction of anaesthesia as the most painful part of the perioperative period ${ }^{4}$.

Ye et al. ${ }^{5}$, demonstrated that ondansetron, a specific 5-hydroxytryptamine antagonist, blocks sodium channels in the rat brain neurons. They also found that ondansetron was 15 timesmore potent than lidocaine in causing numbness when injected under the skin Ondansetron is a well-established agent for prevention of postoperative nausea and vomiting after surgical procedures.

Tramadol is a centrally acting weak $\mu$ - receptor agonist and inhibits nor-adrenaline re-uptake and promotes serotonin release. Wong andCheong reported that pre-treatment with tramadol was as effective as lidocaine in alleviating pain on propofol injection ${ }^{6}$.

However there is relatively very little published data on the efficacy of ondansetron on the pain on injection of propofol. In this study we evaluated the effectiveness of ondansetron and tramadol pre-treatment for alleviation of pain on propofol injection

\section{Materials And Method}

The study was an open label observer blind prospective randomized controlled study of 300 cases. Cases were divided into three groups of 100 each as per group sequential analysis.

Group I: In this group, patients receivedintravenous ondansetron $4 \mathrm{mg}$ in $2 \mathrm{ml}$ normal saline before propofol injection.

Group II: In this group, patients receivedintravenous tramadol $50 \mathrm{mg}$ in $2 \mathrm{ml}$ normal saline before propofol injection.

Group III: In this group, patients received intravenous normal saline $2 \mathrm{ml}$ before propofol injection.

The drugs were given to the patients by investigators according to random number table but the observers taking the readings were blind about the drug given. 
Inclusion Criteria:

Patient undergoing surgeries under general anaesthesia.

ASA grade I and II patients.

Age between 18 to 60 years.

Exclusion criteria:

Patients with ASA grade III and IV.

Patients with history of drug abuse.

Patients undergoing emergency surgeries.

Difficulty in communication.

Patient with history of allergy to propofol or 5HT receptor antagonist.

\section{Study method-}

After institutional ethics committee approval the study was conducted in 300 patients of ASA I and II status and of age group 18-60years presenting for elective surgeries under general anaesthesia. Informed consent was taken. The patients were explained about the procedure during the pre-anaesthetic visit. Patients who had a history of allergic response to either propofol or 5HT receptor antagonist, or received any analgesic or sedative drugs within 24 hours prior to surgery, were excluded from this study. Patients received intravenously either ondansetron pre-treatment $4 \mathrm{mg}$ in a total volume of $2 \mathrm{ml}$ or tramadol pre-treatment $50 \mathrm{mg}$ in total volume $2 \mathrm{ml}$ or $2 \mathrm{ml} 0.9 \%$ saline pre-treatment as a placebo 60 seconds before the administration of propofol according to a randomization list. All drugs were prepared at operating room temperature $\left(21-23^{\circ} \mathrm{C}\right)$ by an anaesthesiologist. No patient was given any premedication or analgesic before the pre-treatment injection.

On arrival in the operation theatre, a $20 \mathrm{G}$ cannula was inserted into a vein on the dorsum of the patient's non-dominant hand and lactated Ringer's solution was infused. Heart rate and non-invasive blood pressure were measured. Heart rate, blood pressure and peripheral oxygen saturation were recorded before injecting propofol and at 1 and $3 \mathrm{~min}$ after. Each patient received $2 \mathrm{ml}$ of the pre-treatment solution for a period of 5 seconds 5 min after i.v. cannulation (time taken for applying monitors) while the venous drainage was occluded manually at mid-arm by an assistant. One minute after intravenous injection of pre-treatment solution, the occlusion was released and anaesthesia was induced with propofol intravenously. The initial $2 \mathrm{ml}$ bolus was given over 5 seconds and the patient was asked to rate immediately any sensation of pain during injection of propofol. Also the verbal response and behavioural response such as facial grimacing, arm withdrawal or tears were noted. The grading of pain was done. Evaluation of pain during injection of propofol was done using Mc Crirrick and Hunter scale ${ }^{7}$ of evaluation of propofolinjection painas shown below.

\begin{tabular}{|l|l|l|}
\hline $\begin{array}{l}\text { PAIN } \\
\text { SCORE }\end{array}$ & $\begin{array}{l}\text { DEGREE OF PAIN/ CONVENTION FOR } \\
\text { STATISTICALCALCULATIONS }\end{array}$ & RESPONSE \\
\hline 0 & NONE / 1 & $\begin{array}{l}\text { Negative response to questioning } \\
\text { any behavioral signs }\end{array}$ \\
\hline 1 & MILD / 2 & $\begin{array}{l}\text { Pain reported in response to questioning and } \\
\text { accompanied by a behavioral sign or }\end{array}$ \\
\hline 2 & MODERATE / 3 & $\begin{array}{l}\text { pain reported spontaneously without questioning } \\
\text { grimacing, arm withdrawal or tears. }\end{array}$ \\
\hline 3 & SEVERE / 4 & \\
\hline
\end{tabular}

Statistical analysis was done using ANOVA test for quantitative data and Chi square test for qualitative data. The statistically significant level was $\mathrm{P}<0.05$.

\section{Results}

The study included 300 patients. The overall incidence of pain was $82.2 \%$ in the saline group, $13.3 \%$ in the tramadol group, and $24.4 \%$ inthe ondansetron group. Pain intensity was significantly less in patients receiving drugs for pre-treatment than those receiving saline $(P=0.001) .4 \mathrm{mg}$ ondansetron, like $50 \mathrm{mg}$ tramadol, significantly reduced the incidence of propofol injection pain. The efficacy of ondansetron in alleviating the incidence and severity of propofol injection pain was no different from tramadol $(P=0.330)$. No significant association was found between gender and pain $(P=0.855)$. 


\section{Discussion}

Propofol is a commonly used intravenous induction agent. It possesses many characteristics of an ideal anaesthetic agent. The most common side effect is pain on injection.

In this study we compared the efficacy of i.v. ondansetron and i.v. tramadol on i.v.propofol injection pain using i.v.saline as control.It was a prospective, randomised, double blind placebo controlled study conducted on 300 patients of ASA I\& II status who were randomly assigned into three groups of 100 each as per group sequential analysis.

Group I - Patients received i.v. ondansetron $(4 \mathrm{mg}: 2 \mathrm{ml})$

Group II - Patients received i.v.tramadol(50mg:2ml)

Group III - Patients received normal saline(2ml)

We found that wheni.v. ondansetron was used as the pre-treatment drug prior to propofol injection, $30 \%$ patients had mild, $16 \%$ moderate and $4 \%$ had severe pain. $50 \%$ patients were painfree.

On pretreatment with i.v. tramadol and subsequent propofol injection $86 \%$ patients were pain free.12\% had mild pain, $2 \%$ experienced moderate, none had severe pain.

On pre-treatment with normal saline and subsequent propofol injection $28 \%$ patients were pain free. $54 \%$ patients had mild, $14 \%$ had moderate and $4 \%$ severe pain. Statistically significant increase in both mean pulse rate and mean arterial pressure from baseline was observed after subsequent propofol injection.

The overall incidence of pain was $82.2 \%$ in thesaline group, $13.3 \%$ in the tramadol group, and $24.4 \%$ inthe ondansetron group. Pain intensity was significantlyless in patients receiving drugs for pre-treatment thanthose receiving saline $(P=0.001) .4 \mathrm{mg}$ ondansetron, like $50 \mathrm{mg}$ tramadol,significantly reduced the incidence of propofol injectionpain. The efficacy of ondansetron in alleviating theincidence and severity of propofol injection pain was nodifferent from tramadol $(P=0.330)$.

\section{Conclusion}

Tramadol and ondansetron significantly reduced the incidence and severity of propofol injection pain more than placebo. The efficacy of ondansetron in alleviating the pain on injection propofol was no different from tramadol.Ondansetron pre-treatment may be used to reduce the incidence of pain on injection of propofol, an advantage added to the useful prevention of postoperative nausea and vomiting.

There is no significant difference between the effectiveness of ondansetron and tramadol in decreasing the pain on injection of propofol. In conclusion, ondansetron pretreatment provides a simple and safe method of reducing propofol injection pain with the advantage of preventing postoperative nausea and vomiting (PONV) and avoiding the administration of other drugs that may be undesirable in certain circumstances.

[1]. Miller r.d. ,Millers anaesthesia ,7th edition, 720-728.

[2]. Sebel P.S., Lowdon J.D., Propofol: a new intravenous anesthetic, Anesthesiology,71, 1989, 260-277.

[3]. Tan C.H. and Onsiong M.K., Pain on injection of propofol, Anaesthesia, 53(5), 1989,468-476.

[4]. Massad I.M., Abu-ali H.M.et al, Venous occlusion with lignocaine for preventing propofol induced pain, Saudi Med journal, 27(70, 2006, 997-1000.

[5]. Ye J. H., Mui W.C., Ren J. et al, Ondanesetron exhibits the properties of a local anaesthetic, Anesthesia Analgesia,85(5), 1997, 1116-1121.

[6]. Wong W. H., Cheong K. F., Role of tramadol in reducing pain on propofol injection, Singapore Med Journal, 42(5), 2001, 193-195.

[7]. A. McCrirrick, S. Hunter, Pain on injection of propofol: the effect of injectate temperature, Anaesthesia, 45, 1990, 443-444 